\title{
PERLINDUNGAN HUKUM ATAS HAK-HAK KELOMPOK AGAMA MINORITAS DI INDONESIA
}

\author{
Bani Syarif Maula \\ Fakultas Syariah IAIN Purwokerto \\ Jl. Ahmad Yani No. 40-A Purwokerto Jawa Tengah \\ banisyarifm@iainpurwokerto.ac.id
}

\begin{abstract}
Abstrak
Kebebasan beragama dan berkeyakinan (freedom of religion and belief) merupakan bagian dari nilai-nilai dasar yang terkandung dalam hak asasi manusia (HAM). Di masa sekarang, konsep tentang HAM secara umum diterima sebagai prinsip bagi semua negara di dunia tanpa memandang ideologi, politik, ekonomi, dan kondisi sosial. Di Indonesia upaya demokratisasi setelah rezim Orde Baru tumbang ternyata tidak sejalan dengan jaminan hak asasi manusia bagi kelompok minoritas, terutama dalam kaitannya dengan kebebasan beragama dan berkeyakinan. Pada tahun 2019, kondisi kebebasan beragama di Indonesia umumnya cenderung negatif dibandingkan tahun sebelumnya. Tulisan ini mengkaji bagaimana perlindungan hukum terhadap hak-hak kelompok agama minoritas dijalankan di Indonesia. Kesimpulan dari kajian tersebut adalah bahwa ada banyak ketentuan dalam UUD 1945 dan dalam sistem hukumnya yang mendukung kebebasan beragama, namun, beberapa adanya kewenangan diskresi yang diberikan kepada pemerintah telah membuat implikasi serius bagi penegarakn hak konstitusional tersebut.
\end{abstract}

Kata Kunci: perlindungan hukum, Hak Asasi Manusia, kebebasan beragama, kelompok minoritas, agama minoritas

\begin{abstract}
Freedom of religion and belief is part of the basic values contained in human rights. At present, the concept of human rights is generally accepted as a principle for all countries in the world regardless of ideology, politics, economy and social conditions. In Indonesia, efforts to democratize after the fall of the New Order regime are not in line with the guarantee of human rights for minority groups, especially in relation to freedom of religion and belief. In 2019, the condition of religious freedom in Indonesia generally tends to be negative compared to the previous year. This paper examines how legal protection of the rights of religious minorities is carried out in Indonesia. The conclusion of this study is that there are many provisions in the 1945 Constitution and in its legal system that support religious freedom, however, some discretionary powers granted to the government have made serious implications for the enforcement of these constitutional rights.
\end{abstract}

Keywords: legal protection, human rights, religiuos freedom, minority group, minority religion 


\section{A. Pendahuluan}

Upaya demokratisasi di Indonesia ternyata tidak sejalan dengan jaminan hak asasi manusia bagi kelompok minoritas, terutama dalam kaitannya dengan kebebasan beragama dan berkeyakinan. Pada tahun 2019, kondisi kebebasan beragama di Indonesia umumnya cenderung negatif dibandingkan tahun sebelumnya. Laporanlaporan dari LSM lokal menunjukkan bahwa provinsi Jawa Barat, DKI Jakarta, dan Jawa Timur mencatat jumlah insiden tertinggi termasuk diskriminasi, ujaran kebencian, tindak kekerasan, dan penolakan izin mendirikan bangunan untuk rumah ibadah bagi penganut agama minoritas. ${ }^{1}$ Pemerintah juga mewajibkan semua warga negara mendaftarkan afiliasi keagamaannya di KTP, yang secara historis memaksa anggota komunitas agama minoritas yang tidak diakui secara resmi untuk menuliskan agama mereka secara keliru karena harus memilih salah satu dari enam agama resmi yang diakui, atau mereka membiarkan kolom agama kosong. Ini dapat berdampak saat mengurus perizinan, pendidikan, dan melamar pekerjaan di lembaga pemerintah. Kebebasan beragama dan berkeyakinan (freedom of religion and belief) merupakan bagian dari nilai-nilai dasar yang terkandung dalam hak asasi manusia.

Nilai-nilai hak asasi manusia (HAM) merupakan nilai-nilai yang tidak secara spesifik terdapat dalam lingkup kebudayaan atau agama-agama tertentu, tetapi merupakan nilai-nilai yang ada di seluruh kebudayaan dan agama di dunia. Hampir seluruh nilai-nilai yang ada di dunia mengagungkan penghormatan pada kehidupan dan martabat manusia. Meskipun demikian, perjuangan untuk mengakui dan menerima HAM merupakan perjuangan panjang, yang seringkali menjadi bagian dari

\footnotetext{
${ }^{1}$ United States Commission on International Religious Freedom, "USCIRF-Recommended for Special Watch List", Indonesia Chapter-2020 Annual Report, https://www.uscirf.gov/reports-briefs/annualreport-chapters-and-summaries/indonesia-chapter2020-annual-report
}

sejarah sosial politik bangsa-bangsa di dunia dan terus mengalami perkembangan. ${ }^{2}$

Di masa sekarang, konsep tentang HAM secara umum diterima sebagai prinsip bagi semua negara di dunia tanpa memandang ideologi, politik, ekonomi, dan kondisi sosial. Karena itulah, ide tentang HAM melampaui setiap aspek hukum internasional sekarang ini, dan ketaatan suatu negara terhadap pemeliharaan HAM dapat mempengaruhi setiap aspek hubungan internasional. Dengan demikian, di dalam negara demokrasi, HAM harus dijamin oleh konstitusi untuk setiap warga negara, di mana negara harus menghormati, melindungi dan memenuhinya. Karena konstitusi adalah hukum tertinggi, maka HAM sebagai hak konstitusional warga negara harus ditegakkan tanpa syarat. Di antara hak asasi yang tercakup dalam konsep HAM yang memerlukan dorongan dunia internasional untuk mewujudkannya karena ditetapkan dalam beberapa deklarasi internasional adalah hak-hak yang terkait dengan kebebasan beragama.

Kebebasan beragama telah dianggap sebagai salah satu hak asasi yang paling dasar, karena hak kebebasan beragama ini merupakan manifestasi dari kebebasan individu (personal liberty) yang berasal dari dalam jiwa setiap manusia. Dengan alasan inilah, gangguan terhadap kebebasan beragama dan kepercayaan (the freedom of religion and belief) seringkali dianggap sebagai pelanggaran yang berat (grave violation). Karena itulah, setiap orang harus mempunyai kebebasan untuk menjalankan dan mempraktekkan kepercayaan mereka tanpa rasa takut atau campur tangan dari orang lain.

Ide dasar dari pemenuhan hak kebebasan beragama berasal dari sejarah perlindungan pemeluk agama minoritas, dan

2 Soetandyo Wignjosoebroto, "Hak Asasi Manusia, Konsep Dasar dan Perkembangan Pengertiannya dari Masa ke Masa”, Seri Bahan Bacaan Kursus HAM untuk Pengacara XVI tahun 2007, Lembaga Studi dan Advokasi Masyarakat (ELSAM). Dokumen dapat diakses di www.elsam.or.id. 
meskipun hak kebebasan beragama tersebut dianggap sebagai fondasi ideologi konsep HAM dari Barat, namun ia sudah diterima secara universal sebagai salah satu fondasi dari masyarakat yang demokratis. Di negaranegara mayoritas Muslim, seperti Indonesia, idealnya kebebasan beragama berarti bahwa pemerintah memberi izin praktek-praktek keagamaan bagi pemeluk agama minoritas atau aliran-aliran lain di samping agama resmi negara, dan tidak mengganggu pemeluk agama/kepercayaan lain tersebut. Namun demikian, dalam kenyataannya, agama minoritas di kedua negara tersebut mengalami pembatasan-pembatasan dalam menjalankan hak asasinya tersebut. Hak kebebasan beragama dan berkeyakinan yang dijamin oleh konstitusi dalam tatanan hukum positif, tidak serta-merta menjamin kebebasan dalam praktek.

Sebagai contoh kasus di Indonesia adalah Peraturan Bersama (Perber) Menteri Agama dan Menteri Dalam Negeri No 8 dan 9 tahun 2006 tentang pendirian rumah ibadah yang menguntungkan dan mempermudah kelompok agama mayoritas dan mempersulit pemeluk agama minoritas. Perber tersebut telah menuai kritikan dari berbagai kalangan, baik dari pemeluk agama Kristen maupun aliran Islam minoritas seperti Ahmadiyah. Peraturan Bersama tersebut telah diajukan uji materi (judicial review) kepada Mahkamah Agung. Selain itu, ada juga Surat Keputusan Bersama antara Menteri Agama, Menteri Dalam Negeri, dan Jaksa Agung tentang peringatan dan perintah kepada penganut, anggota, dan/atau anggota pengurus Jemaat Ahmadiyah Indonesia (JAI) untuk menghentikan semua kegiatan yang tidak sesuai dengan penafsiran agama Islam pada umumnya, seperti pengakuan adanya Nabi setelah Nabi Muhammad SAW. ${ }^{3}$ Para aktivis pembela hak asasi manusia (HAM) langsung bereaksi terhadap SKB 3 Menteri

3 Surat Keputusan Bersama (SKB) Menteri Agama Nomor: 3 Tahun 2008, Jaksa Agung Nomor: Kep-033/A/Ja/6/2008, dan Menteri Dalam Negeri Republik Indonesia Nomor: 199 Tahun 2008. tersebut untuk membela hak konstitusional Ahmadiyah dengan mengajukan uji materi (judicial review) terhadap SKB 3 Menteri tersebut kepada Mahkamah Agung, dan juga mengajukan judicial review terhadap Undang-Undang Nomor 1/PnPs/1965 tentang Pencegahan Penyalahgunaan dan/atau Penodaan Agama yang menjadi dasar dari SKB 3 Menteri tersebut kepada Mahkamah Konstitusi. ${ }^{4}$

Dalam konteks perlindungan HAM, tema ini menemukan relevansi di tengah berbagai kontroversi yang terjadi belakangan ini. Meskipun HAM telah dijamin oleh konstitusi, tetapi dalam setiap pergulatan bernegara oleh masyarakat, nilainilai HAM kerap dikorbankan. Isu-isu di atas menjadi bahan perdebatan yang sengit tidak hanya di antara kelompok masyarakat dan para politisi, tetapi juga telah sampai pada debat mengenai hak konstitusional di Indonesia. Karena itulah, penelitian ini akan mengkaji apakah judicial review sebagai salah satu mekanisme terbaik untuk melindungi hak-hak konstitusional warga negara dapat menjadi cara yang konkret untuk menangani perlindungan hak asasi manusia dengan menguji kekuasaan negara melalui pengadilan.

Tulisan ini mengkaji pokok permasalahan utama berupa gambaran bagaimana perlindungan hukum terhadap hak-hak kelompok agama minoritas di Indonesia, dan apakah aturan perundangundangan di Indonesia telah memberikan peran yang sesuai dengan nilai-nilai Hak Asasi Manusia dalam melindungi hak-hak kelompok agama minoritas.

\section{B. Prinsip Kebebasan Beragama}

Indonesia merupakan anggota Perserikatan Bangsa-Bangsa (PBB) setelah kemerdekaan mereka. Sebagai negara anggota, Indonesia diatur oleh Piagam PBB. Pasal 55 dari Piagam PBB menyatakan salah

\footnotetext{
4 BBC, "SKB Ahmadiyah diterbitkan", diakses dari website: http://www.bbc.co.uk/indonesian/news/story/2008/06 080609 ahmadiyah.shtml
} 
satu tujuan dari Piagam PBB adalah untuk mempromosikan penghormatan universal untuk, dan ketaatan terhadap, hak asasi manusia dan kebebasan dasar bagi semua orang tanpa membedakan ras, jenis kelamin, bahasa atau agama. ${ }^{5}$ Sesuai dengan pasal 56 Piagam PBB, "Semua Anggota berjanji akan mengambil tindakan bersama maupun secara sendiri-sendiri dengan bekerjasama dengan Organisasi ini demi tercapainya tujuantujuan yang tercantum dalam Pasal 55". 6

Pada 1948, Majelis Umum PBB mengeluarkan suatu pernyataan terbesar sedunia mengenai hak asasi manusia yakni The Universal Declaration of Human Rights (UDHR). UDHR ini adalah pernyataan hampir seluruh negara dunia tentang hak dan kebebasan dasar manusia, suatu yang disebut Komisioner Tinggi HAM PBB Mary Robinson sebagai komitmen bersama dunia akan nilai-nilai martabat, persamaan, dan keamanan bagi semua manusia. ${ }^{7}$ Salah satu kebebasan dasar manusia yang berasal dari harkat dan martabat yang melekat dari seorang manusia yang tercantum dalam deklarasi ini adalah kebebasan untuk beragama dan berkeyakinan yang dimuat dalam Pasal 18. ${ }^{8}$ Preamble UDHR sendiri menyatakan bahwa "recognition of the inherent dignity and of the equal inalienable rights of all members of the human family is the foundation of freedom, justice and peace in the world".

Pasal 18 UDHR menyatakan Everyone has the freedom of thought, conscience and religion, this right include freedom to change his religion or belief, and freedom, either alone or in community with others and in public or private to manifest his religion or belief in teaching, practice,

\footnotetext{
5 Piagam Perserikatan Bangsa-Bangsa (Charter of the United Nations), 1945.

6 Piagam Perserikatan Bangsa-Bangsa (Charter of the United Nations), 1945.

7 Mary Robinson, "Making Human Rights Matter: Eleanor Roosevelt's Time Has Come", Harvard Human Rights Journal, Vol. 16, 2003, . 1.

8 Derek H. Davis, "Democracy and the Growth of Religious Liberty as A Universal Human Rights", US Department of State, 2006.
}

worship, and observance. Dalam pasal tersebut terkandung suatu pesan tegas bahwa kebebasan beragama adalah pula meliputi kebebasan untuk beralih/berganti agama serta kebebasan untuk menyatakan agama.

Prinsip yang terkandung bahwa negara menjamin kebebasan setiap warga negara dalam beragama dan berkeyakinan adalah bahwa negara menyatakan kenetralannya dalam hal agama dan sepenuhnya menyerahkan permasalahan agama kepada warga negara. Karena UDHR hanyalah suatu pernyataan (declaration) belaka, ia pada satu sisi tidak memiliki kekuatan mengikat sebagai produk hukum meskipun ia mempunyai kekuatan mengikat secara moral yang amat kuat. ${ }^{9}$

Berbagai hak dan kebebasan dasar termasuk hak beragama dan berkeyakinan ini kemudian dielaborasi ke dalam suatu piranti hukum yang lebih mengikat yakni The International Covenant on Civil and Political Rights (ICCPR). Sementara hakhak lain yang terbilang sebagai hak ekonomi, sosial dan budaya tertuang dalam The International Covenant on Economic Social and Cultural Rights (ICESCR). Dalam Pasal 18 ICCPR dinyatakan bahwa setiap orang berhak atas kebebasan beragama dan berkeyakinan. Hak ini menjadi hak yang amat kukuh dan kuat, karena ICCPR menyatakan bahwa hak beragama dan berkeyakinan ini termasuk dalam non derogable rights, atau hak yang tak dapat dikurangi penikmatannya. Kegagalan untuk melakukan kewajiban yang lahir dari instrumen hukum internasional akan melahirkan apa yang disebut sebagai "pelanggaran hak asasi manusia". 10

Sebelum adanya ICCPR, pada 1961, PBB membentuk suatu kelompok kerja untuk menyusun suatu Convention on Religious Intolerance. Namun demikian, keinginan untuk menjadikannya sebagai

${ }^{9}$ Rhona K. Smith, Textbook on International Human Rights (Oxford: Oxford University Press, 2005), 39.

${ }^{10}$ Knut D. Asplund \& Suparman Marzuki, et.al., (ed), Hukum Hak Asasi Manusia (Yogyakarta: Pusham-UII, 2008), 69. 
suatu perjanjian internasional terhambat karena adanya sensitivitas dan kompleksitas yang tinggi untuk menyusun suatu perjanjian mengenai intoleransi agama yang mengikat secara hukum. Sebagai gantinya, sebuah sub-komisi di bawah Komisi Hak Asasi Manusia PBB menyusun suatu draft deklarasi yang tidak mengikat secara hukum (non-legally binding). ${ }^{11}$

Hingga akhirnya pada 1981 PBB mengesahkan suatu Declaration on The Elimination of All Forms of Intolerance and of Discrimination Based on Religion or Belief (Selanjutnya disebut 'Deklarasi 1981'). ${ }^{12}$ Deklarasi ini adalah suatu instrumen HAM internasional yang memuat istilah religion and belief dalam titelnya. Sebenarnya ini adalah untuk mengakomodasi aspirasi mengenai keagamaan yang menguat di Timur pada satu sisis, dan atheisme di sisi lain.

Sebagaimana UDHR yang pada awalnya tidak disepakati oleh negara-negara yang mengkriminalisasi perbuatan pindah agama, Deklarasi 1981 juga mendapat respon yang tidak seragam. Bulgaria sebagai representasi blok Soviet misalnya, mengajukan keberatan bahwa Deklarasi ini lebih memihak pada mereka yang berkepercayaan dan beragama daripada terhadap mereka yang ateistik Sementara itu, Iran yang mewakili blok agama dari negara peserta PBB melakukan reservasi terhadap Deklarasi ini serta justeru menganggap bahwa Deklarasi ini tidak cukup menjamin agama. ${ }^{13}$

Tanggapan lain dari Deklarasi 1981 muncul dari China di mana Central Committee dari Partai Komunis China yang berkuasa menyatakan bahwa Partai Komunis China adalah atheis, namun menyerukan kebebasan beragama yang terbatas dalam Republik Rakyat China. Menurut

11 Michael M. Roan, "The United Nations: Human Rights and Freedom of Religion or Belief", tanpa tahun, www.tandemproject.com/paper.pdf, 2 .

${ }_{12}$ Diumumkan dengan resolusi Majelis Umum 36/55, 25 November 1981. 2.
Pasal 36 Konstitusi 1982, tak seorangpun boleh menggunakan agama untuk terlibat dalam aktifitas yang mengganggu ketertiban umum, merugikan kesehatan warga negara serta mengganggu sistem pendidikan. ${ }^{14}$

Kebebasan beragama dan berkepercayaan juga dinyatakan dan dijamin dalam berbagai instrumen yang sifatnya regional. Kawasan Eropa misalnya, memilki European Convention on Human Rights di mana dalam perjanjian ini, kebebasan beragama dicantumkan dalam artikel 9 . Mekanisme penegakan konvensi inipun diperkuat dengan adanya Eruopean Court of Human Rights (ECHR). Asia sebagai salah satu kawasan (region) di dunia adalah satusatunya kawasan yang tidak memiliki deklarasi HAM yang di dalamnya mengakui hak beragama. ${ }^{15}$

Ketiadaan instrumen HAM regional di Asia tidak bisa dilepaskan dari sistem politik yang dianut oleh negara-negara di Asia yang masih kental watak dan nuansa feodalnya. Oleh karenanya, pada peringatan ke 50 Deklarasi Hak Asasi Manusia Sedunia, yang diselenggarakan di Kwangju Korea Selatan, para perwakilan rakyat Asia mendeklarasikan Asian Charter of Human Rights. Oleh karenanya pula, Asian Human Rights Charter ini pula disebut sebagai $A$ People's Charter. Deklarasi HAM Asia ini menyatakan sebagai berikut:

"the freedom of religion and conscience is particularly important in Asia where most people are deeply religious. Religion is source of comfort and solace in the midst of poverty and oppression. However religious fundamentalism is also a cause of divisions and conflict. Religious tolerance is essential for the enjoyment of the right of

\footnotetext{
${ }^{14}$ Michael M. Roan, "The United Nations”, .

2.. $\quad 15$ Bani Syarif Maula, "Religious Freedom in Indonesia: Between Upholding Constitusional Provisions and Complying with Social Considerations", Journal of Indonesian Islam, Vol. 7, No. 2, December 2013, . 383.
} 
conscience of others which includes the right to change one's belief'.

Sebagai hak yang tercantum dalam pasal pertama Bill of Rights, dapat disimpulkan bahwa kebebasan ini adalah kebebasan yang menempati posisi yang teramat penting. ${ }^{16}$ Begitu pentingnya hak ini, sehingga sebelum berkecamuknya Perang Dunia II, Presiden Roosevelt menyatakan bahwa terjaminnya kebebasan beragama inilah yang menjadikan keharusan bagi Amerika untuk terlibat dalam perang di Eropa. $^{17}$

Namun, meskipun konsep HAM memainkan peran penting dalam tingkat internasional, dalam prakteknya faktorfaktor internasional benar-benar memiliki sedikit atau bahkan tidak berpengaruh pada penghormatan terhadap HAM dalam negeri. Camp Keith, misalnya, berpendapat bahwa tidak ada korelasi statistik antara ratifikasi ICCPR dan peningkatan penghormatan terhadap hak asasi manusia. ${ }^{18}$ Demikian pula, kajian Hathaway tentang berbagai perjanjian hak asasi manusia internasional, menegaskan temuan ini. Hathaway menyimpulkan bahwa perjanjian ratifikasi tidak hanya efektif, tetapi pada waktu tertentu benar-benar dapat menghasilkan hasil negatif: "perjanjian ratifikasi tidak jarang dikaitkan dengan HAM yang buruk, bukan peringkat yang lebih baik, dari yang seharusnya dapat diharapkan". ${ }^{19}$ Landman juga datang untuk mempertanyakan efektivitas sejati perjanjian hak asasi manusia internasional. Secara khusus, ia

16 Eugenia R. Pastor, "The Flawed Implementation of The International Religious Freedom Act of 1998: A European Perspective", Brigham Young University Law Review, 2005, . 711.

17 M.E. Parmly, "Religious Freedom Across the Atlantic: Developing the Habit of Cooperation," pidato dalam The Institute of Religion and Public Policy's Conference on Transatlantic Conversation on Religious Coexistence, 26 April 2001.

${ }^{18}$ Linda Camp Keith, "Judicial Independence and Human Rights Protection around the World." Judicature, Vol. 85, No. 4, 2002, . 195 - 200.

19 Oona A. Hathaway, "Do Human Rights Treaties Make a Difference?" The Yale Law Journal, 111,2002, . 1935-2042. menemukan bahwa efek dari penandatanganan atau meratifikasi perjanjian tersebut pada penghormatan terhadap hak asasi manusia dalam negeri tidak cukup kuat yang dapat menanamkan optimisme tentang efektivitas masa depan perjanjian hak asasi manusia internasional. ${ }^{20}$

Namun demikian, Stahnke dan Blitt mengatakan bahwa di bawah standar hak asasi manusia internasional, negara dapat mengadopsi hubungan tertentu dengan agama mayoritas penduduk, termasuk mendirikan agama negara, asalkan hubungan tersebut tidak mengakibatkan pelanggaran hak-hak sipil dan politik dari, atau diskriminasi terhadap, penganut agama lain atau non-Muslim. ${ }^{21}$ Namun, banyak pelanggaran hak asasi manusia terjadi di negara-negara Muslim apapun pengakuan konstitusional mereka dari agama negara. Indonesia adalah salah satu di antara negaranegara Muslim yang membatasi hak untuk kebebasan berpikir, hati nurani, dan agama atau kepercayaan (freedom of thought, conscience, and religion or belief), meskipun negara Indonesia memiliki ketentuan konstitusional mengenai perlindungan hak asasi manusia.

\section{Kebebasan Beragama di Indonesia}

Menurut Stahnke dan Blitt, ada empat kategori negara yang memiliki mayoritas penduduk Muslim. Yang pertama adalah negara-negara yang menyatakan diri sebagai negara Islam; kategori kedua adalah negara-negara yang menyatakan Islam sebagai agama resmi negara; yang ketiga adalah negara yang menyatakan diri mereka sebagai negara sekuler; dan kategori keempat adalah negara yang belum membuat pernyataan konstitusional tentang

${ }^{20}$ Todd Landman, Protecting Human Rights: A Comparative Study (Washington DC: Georgetown University Press, 2005), 73.

${ }^{21}$ Tad Stahnke and Robert C. Blitt, "The Religion-State Relationship and the Right to Freedom of Religion or Belief: A Comparative Textual Analysis of the Constitution of Predominantly Muslim Countries", Georgetown Journal of International Law, Vol. 36, 2005, 947-1078. 
sifat Islam atau sekuler, dan tidak menjadikan Islam sebagai agama resmi negara. ${ }^{22}$ Indonesia merupakan bagian dari kategori terakhir.

Indonesia adalah negara mayoritas Muslim dengan sistem negara yang sekuler. Tidak adanya referensi Islam dalam UUD 1945 menunjukkan bahwa Indonesia terbuka untuk semua agama selain Islam. Hal ini sesuai dengan norma-norma hak asasi manusia internasional yang menetapkan, antara lain, bahwa pemerintah tidak hanya dilarang membatasi kebebasan beragama, tetapi juga tidak dapat diterima--sesuai dengan standar Internasional demokrasi-untuk mendukung agama tertentu.

Konstitusi Indonesia memberikan kebebasan beragama, dan pemerintah umumnya menghormati hak ini dalam praktek, terutama sejak amandemen konstitusi Indonesia pada tahun 2000. Kebebasan beragama merupakan amanat dari UUD 1945 yang dijamin dalam pasal 28E UUD 1945 yang berbunyi ayat (1) Setiap orang bebas memeluk agama dan beribadat menurut agamanya, memilih pendidikan dan pengajaran, memilih pekerjaan, memilih kewarganegaraan, memilih tempat tinggal di wilayah negara dan meninggalkannya, serta berhak kembali; Ayat (2) Setiap orang berhak atas kebebasan meyakini kepercayaan, menyatakan pikiran dan sikap, sesuai dengan hati nuraninya." Juga diperkuat dengan Pasal 29 UUD 1945 Ayat (2) yang berbunyi "Negara menjamin kemerdekaan tiap-tiap penduduk untuk memeluk agamanya masing-masing dan untuk beribadat menurut agamanya dan kepercayaannya itu."

Namun demikian, jaminan konstitusi atas kebebasan beragama belum sepenuhnya terlaksana dengan baik di dalam prakteknya. Pembatasan terus ada pada

${ }^{22}$ Tad Stahnke and Robert C. Blitt, "The Religion-State Relationship and the Right to Freedom of Religion or Belief: A Comparative Textual Analysis of the Constitution of Predominantly Muslim Countries", Georgetown Journal of International Law, Vol. 36, 2005, 947-1078. beberapa jenis kegiatan keagamaan. Selain itu, menurut sebuah laporan yang dirilis oleh Departemen Luar Negeri AS, aparat keamanan bahkan terkadang melakukan diskriminasi dan pelecehan terhadap kelompok agama minoritas dan pemerintah gagal menghukum pelakunya. ${ }^{23}$ Menurut Setara Institute, terdapat 216 kasus serangan terhadap minoritas agama pada 2010, 244 kasus pada 2011, dan 264 kasus pada 2012. ${ }^{24}$ Wahid Institute juga mendokumentasikan 92 pelanggaran terhadap kebebasan agama dan 184 peristiwa intoleransi beragama pada 2011, naik dari 64 pelanggaran dan 134 peristiwa intoleransi pada $2010 .^{25}$

Kondisi ini bisa disebabkan, antara lain, oleh kebijakan pemerintah dan aturan hukum yang memperketat kebebasan beragama jika kondisi berubah. Gvosdev mengatakan bahwa beberapa negara 'demokratis' memiliki beberapa strategi di mana pemerintah secara legal dapat membatasi kebebasan beragama. Menurut Gvosdev, metode yang paling jelas adalah penyisipan aturan terkait dengan kepentingan negara ke dalam konstitusi yang memberikan kepada pemerintah kekuasaan untuk melarang kelompok dan praktek-praktek keagamaan yang dianggap bertentangan dengan tujuan negara. ${ }^{26}$ Dalam

23 U.S. Department of State, Bureau of Democracy, Human Rights and Labour, Indonesia 2019 International Religious Freedom Report, diakses dari: https://www.state.gov/wpcontent/uploads/2020/06/INDONESIA-2019-

INTERNATIONAL-RELIGIOUS-FREEDOM$\frac{\text { REPORT.pdf }}{24 \text { Set }}$

Beragama dan Berkeyakinan 2007-2011,"

http://www.setara-

institute.org/en/category/galleries/indicators

${ }^{25}$ Wahid Institute, "Laporan Kebebasan Beragama/Berkeyakinan dan Toleransi the Wahid Institute Tahun 2011", http://www.wahidinstitute.org/wi-id/laporan-danpublikasi/laporan-tahunan-kebebasan-beragama-danberkeyakinan/154--laporan-kebebasan-

beragamaberkeyakinan-dan-toleransi-the-wahid$\frac{\text { institute-tahun-2011-.html }}{26}$

26 Nikolas K. Gvosdev, “Constitutional Doublethink, Managed Pluralism and Freedom of 
kasus Indonesia, Gvosdev menemukan bahwa pemerintah Indonesia telah memberlakukan beberapa aturan yang mendefinisikan 'kebebasan beragama' secara sempit atau lebih terbatas daripada pemahaman umum. $^{27}$ Oleh karena itu, pemerintah Indonesia sebenarnya telah mempertahankan hak untuk menentukan agama apa yang harus ada di negara itu, dan telah dipastikan melalui kebijakankebijakannya bahwa warganya hanya boleh mengikuti keyakinan agama yang dapat diterima oleh negara. $^{28}$

Oleh karena itu, meskipun konstitusi Indonesia menjamin kebebasan beragama warganya, ketentuan tersebut harus ditafsirkan sebagai 'kebebasan beribadah', bukan 'kebebasan untuk menjalankan keyakinan mereka', karena pemerintah secara resmi hanya mengakui enam agama, dan pembatasan juga masih berlanjut pada jenis kegiatan keagamaan tertentu, khususnya di kalangan agama yang tidak diakui dan aliran agama yang dianggap "menyimpang". 29

\section{Upaya Hukum untuk Menjamin Kebebasan Beragama}

Salah satu prinsip pokok bagi negara hukum di masa modern sekarang ini adalah adanya perlindungan konstitusional terhadap hak asasi manusia dengan jaminan hukum bagi tuntutan penegakannya melalui proses yang adil. Perlindungan terhadap hak asasi manusia tersebut dimasyarakatkan secara luas dalam rangka mempromosikan penghormatan dan perlindungan terhadap

Religion", Religion, State \& Society, Vol. 29, No. 2, 2001.

27 Ibid.

28 Rita Smith Kipp \& Susan Rodgers, "Introduction: Indonesian Religions in Society", in Rita Smith Kipp \& Susan Rodgers (eds), Indonesian Religions in Transition (Tucson: University of Arizona Press, 1987), hlm. 23.

${ }^{29}$ Bani Syarif Maula, "Religious Freedom in Indonesia and Malaysia in the Constitutional Comparative Perspective (The Cases of Judicial Review in Blasphemous Offences)", Al-Manahij: Jurnal Kajian Hukum Islam, Vol. 6, No. 1, Juni 2012, hlm. 55-70. hak-hak asasi manusia sebagai cirri yang penting suatu negara hukum yang demokratis. Terbentuknya negara dan demikian pula penyelenggaraan kekuasaan suatu negara tidak boleh mengurangi arti atau makna kebebasan dan hak-hak asasi manusia. Jika dalam suatu negara hak asasi manusia terabaikan atau dilanggar dengan sengaja dan penderitaan yang ditimbulkannya tidak dapat diatasi secara adil, maka negara yang bersangkutan tidak dapat disebut sebagai negara hukum dalam arti yang sesungguhnya. ${ }^{30}$

Dalam perspektif teori konstitusi, dianutnya sistem judicial review merupakan suatu bentuk dan upaya penguatan konsep negara hukum yang menempatkan konstitusi sebagai hukum tertinggi. Hal ini sejalan dengan teori stufenbau yang dikemukakan oleh Hans Kelsen yang menjelaskan bahwa tatanan hukum itu merupakan sistem norma yang hierarkis atau bertingkat, di mana norma hukum yang paling rendah harus berpegangan pada norma hukum yang lebih tinggi, dan kaidah hukum yang tertinggi (seperti konstitusi) harus berpegangan pada norma hukum yang paling mendasar (grundnorm). Menurut Kelsen norma hukum yang paling dasar (grundnorm) bentuknya tidak kongkrit (abstrak). Dengan demikian, dalam hierarki tatanan hukum, kaidahkaidah hukum dari tingkatan yang lebih rendah memperoleh kekuatan dari kaidah hukum yang lebih tinggi tingkatannya. ${ }^{31}$

Dasar ide akan adanya mekanisme judicial review adalah bagaimana caranya memaksa pembentuk peraturan perundangundangan agar taat terhadap norma hukum yang tertuang dalam peraturan tingkat atasnya dan agar terbentuk peraturan perundang-undangan yang selaras dengan ketentuan dalam konstitusi. ${ }^{32}$ Sebagai

\footnotetext{
30 Jimly Asshiddiqie, Konstitusi dan Konstitusionalisme Indonesia, cet. 2 (Jakarta: Konstitusi Press, 2006), hlm. 159-160.

${ }^{31}$ Abdul Latif, dkk, Hukum Acara Mahkamah Konstitusi (Yogyakarta: Total Media, 2009), hlm. 9.

32 Mahfud MD., "Mengawal Arah Politik Hukum: Dari Prolegnas Sampai Judicial Review",
} 
hukum tertinggi, konstitusi harus memberi perlindungan hak asasi manusia, karena jaminan tersebut merupakan salah satu kewajiban negara. Sebagai pemenuhan hak konstitusional untuk melindungi, menjamin dan mewujudkan hak asasi yang terdapat di dalam konstitusi tersebut dibutuhkan lembaga yang kuat serta menjaga supremasi konstitusi sebagai hukum tertinggi suatu negara. Menurut Danie Brand bahwa cara yang paling konkret untuk menjamin perlindungan hak asasi manusia adalah dengan membatasi kewenangan negara dalam konstitusi melalui pengadilan. ${ }^{33}$

Pengujian undang-undang dan konsitusi melalui pengadilan merupakan salah satu mekanisme terbaik dalam jaminan perlindungan hak-hak beragama dan berkeyakinan kelompok agama minoritas. Hak-hak konstitusi tersebut tidak akan berarti jika tidak ada mekanisme penegakannya, dan satu-satunya lembaga yang paling penting dalam perlindungan hak asasi manusia adalah lembaga peradilan, yang di Indonesia dijalankan oleh Mahkamah Konstitusi (dan Mahkamah Agung untuk aturan di bawah undangundang). Hal ini sejalan dengan pendapat Hans Kelsen yang mengatakan tentang validitas sebuah aturan bahwa pelaksanaan aturan konstitusional tentang legislasi dapat secara efektif dijamin hanya jika suatu organ selain badan legislatif diberikan tugas untuk menguji apakah suatu produk hukum itu konstitusional atau tidak, dan tidak memberlakukannya jika menurut organ ini produk badan legislatif tersebut tidak konstitusional. ${ }^{34}$

Pelaksanaan aturan konstitusional tentang legislasi dapat secara efektif dijamin

http://www.mahfudmd.com/public/makalah/Makalah 26.pdf

Danie Brand, "Introduction to SocioEconomic Rights in the South African Constitution", dalam Christof Heyns \& Danie Brand (eds.), SocioEconomic Rights in South Africa (Pretoria: Pretoria University Law Press, 2005), hlm. 38-39.

34 Jimly Asshiddiqie \& Ali Safa'at, Teori Hans Kelsen tentang Hukum, cet. 1 (Jakarta: Setjen \& Kepaniteraan MK-RI, 2006), hlm. 139. hanya jika suatu organ selain badan legislatif diberikan tugas untuk menguji apakah suatu hukum itu konstitusional atau tidak, dan tidak memberlakukannya jika menurut pendapat organ ini tidak konstitusional. Organ yang mengontrol tersebut dapat menghapuskan secara keseluruhan undangundang yang tidak konstitusional sehingga tidak dapat diaplikasikan oleh organ lain. Jika suatu pengadilan biasa memiliki kompetensi menguji konstitusionalitas undang-undang, mungkin hanya dalam bentuk menolak untuk menerapkannya dalam kasus konkret ketika menyatakan bahwa undang-undang tersebut tidak konstitusional sedangkan organ lain tetap diwajibkan menerapkannya. Sepanjang suatu undang-undang belum dibatalkan (annuled) maka ia adalah konstitusional. Yang dikatakan sebagai hukum tidak konstitusional adalah bukan batal ab initio, tetapi hanya dapat dibatalkan, yaitu dapat tidak diberlakukan berdasarkan alasan tertentu. ${ }^{35}$

George Jellinek, sebagaimana diceritakan Asshiddiqie dan Safa'at, pada akhir abad ke-19 mengembangkan gagasan agar kewenangan judicial review tersebut diterapkan di Austria, seperti yang telah diterapkan oleh John Marshal di Amerika. Pada tahun 1867, Mahkamah Agung Austria mendapatkan kewenangan menangani sengketa yuridis terkait dengan perlindungan hak-hak politik berhadapan dengan pemerintah. Pemikiran Hans Kelsen mendorong dibentuknya suatu lembaga yang diberi nama Verfassungsgerichtshoft atau Constitutional Court (Mahkamah Konstitusi) yang berdiri sendiri di luar Mahkamah Agung, sehingga model ini sering disebut sebagai "The Kelsenian Model". ${ }^{36}$

Konsep judicial review telah menjadi aspek yang wajib dari pemerintahan yang demokratis, karena dapat memberikan perlindungan hukum yang pasti bagi warga negara terhadap kesewenang-wenangan

\footnotetext{
${ }^{35}$ Ibid., hlm. 139-140.

${ }^{36}$ Ibid., hlm. 140.
} 
kekuasaan negara. Judicial review sebagai lembaga yang berasal dari Amerika Serikat dua abad yang lalu telah menyebar ke seluruh dunia dalam setengah abad terakhir. Pada tahun 2005, lebih dari tiga-perempat negara di dunia memiliki beberapa bentuk judicial review untuk konstitusionalitas yang dituangkan dalam konstitusi mereka. ${ }^{37}$

Judicial review dilakukan baik oleh pengadilan konstitusi khusus seperti Mahkamah Konstitusi di Indonesia. Judicial review adalah contoh dari fungsi pemisahan kekuasaan dalam sistem pemerintahan modern (di mana lembaga peradilan adalah salah satu dari beberapa cabang kekuasaan negara). Prinsip ini ditafsirkan berbeda dalam yurisdiksi yang berbeda, yang juga memiliki pandangan yang berbeda pada hirarki yang berbeda dari suatu norma pemerintahan. Akibatnya, prosedur dan lingkup judicial review juga berbeda dari satu negara ke negara lainnya. ${ }^{38}$

Justifikasi yang dominan bagi kuatnya posisi mahkamah konstitusi (constitutional court) didasarkan pada peran pengadilan tersebut dalam memberi perlindungan atas hak-hak individu; khususnya, hak-hak yang secara eksplisit tercantum dalam konstitusi. Telah diterima secara umum bahwa mahkamah konstitusi (constitutional court) harus memiliki kekuatan yang besar untuk memantau konstitusionalitas undang-undang jika hak-hak konstitusional warga negara menjadi perhatian utama. Argumen yang paling populer yang digunakan untuk mendukung keberadaan mahkamah konstitusi yang kuat adalah bahwa demokrasi tidak didasarkan pada penghormatan secara buta terhadap kehendak mayoritas, meskipun hak individu dan minoritas merupakan salah satu masalah yang paling utama bagi warga mayoritas. Politik mayoritas mampu menjaga

37 Donald L. Horowitz, "Constitutional Courts: A Primer for Decision Makers", Journal of Democracy, Vol. 17, No. 4, 2006, pp. 125-137, diakses dari: http://muse.jhu.edu/journals/journal_of_democracy/v $\underline{017 / 17.4 \text { horowitz.html }}$

$$
{ }^{38} \text { Ibid. }
$$

kepentingannya sendiri, tetapi memberikan perlindungan yang cukup terhadap kaum minoritas dan suara individu, baik suara tersebut dipahami dalam hal politik, moral, maupun agama, sulit untuk dilaksanakan. Menurut Sadurski, mayoritas seharusnya tidak diperbolehkan untuk selalu menang atas orang-orang yang tidak setuju dengan preferensi dan pilihan, dan nilai-nilai yang terkandung dalam hak-hak konstitusional mencerminkan adanya batasan bagi mayoritas. ${ }^{39}$ Karena mayoritas tidak dapat dipercaya untuk mengamati batas-batas yang telah ditentukan atas kekuasaannya, maka sebuah lembaga non-mayoritas yang independen diperlukan untuk mengawasi, memantau dan menegakkan batas-batas tersebut. $^{40}$

Struktur pemerintahan sangat menentukan sistem judicial review. Struktur pemerintahan Indonesia berbentuk pemisahan kekuasaan (separation of powers). Hal ini menjadi dasar untuk membuat rule of law, setidaknya dalam bentuknya yang dasar. Di Indonesia, setelah eksekutif, parlemen, dan Mahkamah Agung dipisahkan dan ditempatkan pada tingkat yang sama secara struktural, Mahkamah Agung hanya diberikan kekuasaan untuk melakukan pengujian (review) hukum di bawah undang-undang; sedangkan hukum yang dibuat oleh parlemen dapat dilakukan pengujian (review) oleh Mahkamah Konstitusi. $^{41}$

Fakta bahwa Mahkamah Agung diberikan kekuasaan untuk melakukan judicial review atas ketentuan hukum yang dibuat oleh eksekutif di Indonesia dapat dilihat dalam kasus penerbitan Surat Keputusan Bersama yang membatasi

${ }^{39}$ Wojciech Sadurski, Rights before Courts: A Study of Constitutional Courts in Post-Communist States of Central and Eastern Europe (The Netherlands: Springer, 2005), hlm. 107.

${ }^{40}$ Ibid.

${ }^{41}$ Y. Zhang, "Comparative Studies on Judicial Review in East and Southeast Asia", IIAS Symposium, 31 August-1 September, 1995, Leiden, The Netherlands. Diakses dari: http://www.iias.nl/iiasn/iiasn6/iiasnews/zhang.html 
praktek kebebasan beragama dari kelompok minoritas Ahmadiyah.

Dalam kasus pembatasan kebebasan beragama, meskipun konstitusi memberikan kebebasan beragama dan pemerintah biasanya menghargai hak ini, dalam praktek baik pemerintah Indonesia melakukan beberapa pembatasan atas hak ini. Di Indonesia percaya kepada Tuhan Yang Maha Esa adalah salah satu dasar negara; damun, praktek keyakinan Islam selain Islam Sunni dibatasi secara signifikan di kedua negara tersebut. Argumen yang mendukung pandangan ini terletak pada alasan relativisme budaya, yang dibingkai dalam hal 'nilai-nilai Asia'. Para pemimpin kedua negara tersebut berpendapat bahwa dalam konteks sosial, lebih penting untuk menjaga keharmonisan sosial dan kesejahteraan bersama dari pada menegakkan gagasan Barat tentang hak asasi manusia yang berfokus pada hak individu. $^{42}$

Karena itu, ketika pemerintah Indonesia memberlakukan keputusan menteri yang mengatur pendirian tempat ibadah, atau mengeluarkan surat keputusan bersama yang melarang anggota Ahmadiyah untuk menyebarkan penafsiran dan kegiatan yang dianggap menyimpang dari pokokpokok ajaran Islam, alasan di balik penerbitan keputusan tersbut adalah untuk menjaga ketertiban umum dan memelihara keharmonisan sosial.

Namun demikian, tujuan dari peraturan-peraturan tersebut, yang menunjukkan tanggung jawab negara untuk menjamin hak semua warga negara atas kebebasan beragama atau berkeyakinan, tidak tercapai dan mengakibatkan ketidakpuasan masyarakat. Kondisi ini dapat disebabkan oleh fakta bahwa peraturan tersebut hanya memenuhi tuntutan agama mayoritas, di mana umat Islam merupakan mayoritas di Indonesia. Oleh karena itu,

42 Shad S. Faruq, "Human rights and the Constitution", dalam Ramdas Tikamdas \& S.S. Rachgan (eds), Human Rights and the National Commission (Kuala Lumpur: Hakam, 1999), hlm. 185. peraturan tersebut pada umumnya bertentangan dengan kepentingan nonMuslim atau agama minoritas lain. Karena fakta ini, masyarakat yang tidak puas dengan kebijakan pemerintah dapat mengajukan judicial review untuk menegakkan hak-hak mereka atas kebebasan beragama.

Banyak pengamat yang mencatat bahwa di masa konstitusionalisme, orangorang di seluruh dunia beralih ke pengadilan untuk melakukan proses judicial review demi melindungi hak-hak dasar mereka. ${ }^{43}$ Ketersediaan bab tentang kebebasan fundamental, adanya aturan-aturan yang menyatakan supremasi konstitusi dan judicial review di negara-negara demokrasi adalah dimaksudkan untuk mencapai keseimbangan yang adil antara kebutuhan untuk kebebasan dan kebutuhan untuk ketertiban dan stabilitas sosial. Isu-isu HAM dan judicial review telah menjadi instrumen pilihan untuk mendamaikan persaingan kepentingan antar individu yang berbagi 'ruang bersama' (common space) secara fisik dan sosial, karena memelihara aturan hukum tentang hak-hak warga negara ke dalam kerangka konstitusi dapat menjamin hak-hak dasar manusia dan kebebasan, setidaknya sebagai alat bagi pemerintah dalam menjaga keharmonisan sosial dengan memenuhi standar keadilan. ${ }^{44}$

\section{E. Penutup}

Ada banyak ketentuan dalam Konstitusi Indonesia (UUD 1945) dan dalam sistem hukumnya yang mendukung hak asasi manusia. Bab tentang kebebasan mendasar, ketentuan untuk supremasi konstitusi dan judicial review dimaksudkan untuk mencapai keseimbangan yang adil antara kebutuhan akan kebebasan dan kebutuhan akan ketertiban dan stabilitas. Namun, beberapa ketentuan tentang

${ }^{43}$ David M. Beatty, "Human Rights and the Rules of Law", dalam David M. Beatty (ed.), Human Rights and Judicial Review: A Comparative Perspective (London: Martinus Nijhoff Publishers, 1994), hlm. 1-2.

${ }^{44}$ Ibid. 
kewenangan diskresi yang diberikan kepada pemerintah telah membuat implikasi serius bagi hak asasi manusia. Di negara yang demokratis, pengadilan memiliki kekuatan untuk menilai "kewajaran" suatu kebijakan hukum dan menyatakan bahwa kebijakan yang keras, kejam, dan menindas tidaklah konstitusional. Secara teoritis, Indonesia dengan Mahkamah Konstitusi telah mencapai idealita itu.

Indonesia memiliki beberapa karakteristik ketentuan konstitusional tentang perlindungan kebebasan beragama. Konstitusi Indonesia tidak mengandung referensi khusus untuk agama apa pun, yang berarti semua agama dan kepercayaan memiliki status yang sama dalam Konstitusi. Setiap upaya untuk melarang kebebasan beragama tertentu akan dipandang melanggar konstitusi. Karena itu, judicial review atas kebijakan eksekutif dan kebijakan legislatif sangat mungkin untuk dapat melindungi hak-hak minoritas agama di Indonesia.

Idealnya, kekuatan judicial review dapat berfungsi sebagai sarana penting untuk pengujian undang-undang terhadap tirani mayoritas, dan itu harus diletakkan sebagai faktor penting dalam perlindungan hak asasi manusia; namun, secara empiris, harapan bahwa pengadilan yang melaksanakan kekuasaan judicial review dapat berfungsi sebagai penjamin hak asasi manusia individu belum terwujud seperti yang diharapkan.

\section{DAFTAR PUSTAKA}

Asplund, Knut D. \& Suparman Marzuki, et.al. (ed). Hukum Hak Asasi Manusia. Yogyakarta: Pusham-UII, 2008.

Asshiddiqie, Jimly. Pokok-Pokok Hukum Tata Negara Indonesia Pasca Reformasi. Jakarta: PT. Bhuana Ilmu Populer-BIP, 2007.

Asshiddiqie, Jimly. Hukum Acara Pengujian Undang-Undang, cet. 3. Jakarta: Setjen \& Kepaniteraan MK-RI, 2006.
Asshiddiqie, Jimly. Konstitusi dan Konstitusionalisme Indonesia, cet. 2. Jakarta: Konstitusi Press, 2006.

Asshiddiqie, Jimly, \& Ali Safa'at, Teori Hans Kelsen tentang Hukum, cet. 1. Jakarta: Setjen \& Kepaniteraan MKRI, 2006.

Beatty, David M. (ed.). Human Rights and Judicial Review: A Comparative Perspective. London: Martinus Nijhoff Publishers, 1994.

BBC, "SKB Ahmadiyah diterbitkan", diakses dari website: http://www.bbc.co.uk/indonesian/news /story/2008/06/080609 ahmadiyah.sht $\underline{\mathrm{ml}}$

Brand, Danie. "Introduction to SocioEconomic Rights in the South African Constitution", dalam Christof Heyns \& Danie Brand (eds.). SocioEconomic Rights in South Africa Pretoria: Pretoria University Law Press, 2005.

Davis, Derek H. "Democracy and the Growth of Religious Liberty as A Universal Human Rights", US Department of State, 2006.

Faruq, Shad S. "Human Rights and the Constitution", dalam Ramdas Tikamdas \& S.S. Rachgan (eds). Human Rights and the National Commission. Kuala Lumpur: Hakam, 1999.

Gvosdev, Nikolas K. "Constitutional Doublethink, Managed Pluralism and Freedom of Religion", Religion, State \& Society, Vol. 29, No. 2, 2001.

Hathaway, Oona A. "Do Human Rights Treaties Make a Difference?" The Yale Law Journal, 111, 2002.

Heyns, Christof, \& Danie Brand (eds.). Socio-Economic Rights in South Africa. Pretoria: Pretoria University Law Press, 2005. 
Horowitz, Donald L. "Constitutional Courts: A Primer for Decision Makers", Journal of Democracy, Vol. 17, No. 4, 2006, pp. 125-137, diakses dari: http://muse.jhu.edu/journals/journal o f democracy/v017/17.4horowitz.html

Keith, Linda Camp. "Judicial Independence and Human Rights Protection around the World." Judicature, Vol. 85, No. 4, 2002.

Kipp, Rita Smith, \& Susan Rodgers. "Introduction: Indonesian Religions in Society", in Rita Smith Kipp \& Susan Rodgers (eds), Indonesian Religions in Transition. Tucson: University of Arizona Press, 1987.

Landman, Todd. Protecting Human Rights: A Comparative Study. Washington DC: Georgetown University Press, 2005.

Latif, Abdul, dkk. Hukum Acara Mahkamah Konstitusi. Yogyakarta: Total Media, 2009.

Mahfud MD., Mohamad. "Mengawal Arah Politik Hukum: Dari Prolegnas Sampai Judicial Review", http://www.mahfudmd.com/public/ makalah/Makalah 26.pdf

Marzuki, Peter Mahmud. Penelitian Hukum, cet. 3. Jakarta: Kencana Prenada Media, 2007.

Maula, Bani Syarif. "Religious Freedom in Indonesia and Malaysia in the Constitutional Comparative Perspective (The Cases of Judicial Review in Blasphemous Offences)", Al-Manahij: Jurnal Kajian Hukum Islam, Vol. 6, No. 1, Juni 2012.

Maula, Bani Syarif. "Religious Freedom in Indonesia: Between Upholding Constitusional Provisions and Complying with Social Considerations", Journal of Indonesian Islam, Vol. 7, No. 2, December 2013.
Parmly, M.E. "Religious Freedom across the Atlantic: Developing the Habit of Cooperation," pidato dalam The Institute of Religion and Public Policy's Conference on Transatlantic Conversation on Religious Coexistence, 26 April 2001.

Pastor, Eugenia R. "The Flawed Implementation of the International Religious Freedom Act of 1998: A European Perspective", Brigham Young University Law Review, 2005.

Piagam Perserikatan Bangsa-Bangsa (Charter of the United Nations), 1945

Roan, Michael M. "The United Nations: Human Rights and Freedom of Religion or Belief", tanpa tahun, www.tandemproject.com/paper.pdf.

Robinson, Mary. "Making Human Rights Matter: Eleanor Roosevelt's Time Has Come", Harvard Human Rights Journal, Vol. 16, 2003.

Sadurski, Wojciech. Rights before Courts: A Study of Constitutional Courts in PostCommunist States of Central and Eastern Europe. The Netherlands: Springer, 2005.

Smith, Rhona K. Textbook on International Human Rights. Oxford: Oxford University Press, 2005.

Stahnke, Tad, \& Robert C. Blitt. "The Religion-State Relationship and the Right to Freedom of Religion or Belief: A Comparative Textual Analysis of the Constitution of Predominantly Muslim Countries", Georgetown Journal of International Law, Vol. 36, 2005, hlm. 947-1078.

Surat Keputusan Bersama (SKB) Menteri Agama Nomor: 3 Tahun 2008, Jaksa Agung Nomor: Kep-033/A/Ja/6/2008, dan Menteri Dalam Negeri Republik Indonesia Nomor: 199 Tahun 2008.

Tikamdas, Ramdas, \& S.S. Rachgan (eds). Human Rights and the National 
Commission. Kuala Lumpur: Hakam, 1999.

United States Commission on International Religious Freedom, "USCIRFRecommended for Special Watch List", Indonesia Chapter-2020 Annual Report, diakses dari: https://www.uscirf.gov/reportsbriefs/annual-report-chapters-andsummaries/indonesia-chapter-2020annual-report

United States Department of State, Bureau of Democracy, Human Rights and Labour, Indonesia 2019 International Religious Freedom Report, diakses dari: https://www.state.gov/wpcontent/uploads/2020/06/INDONESIA -2019-INTERNATIONALRELIGIOUS-FREEDOMREPORT.pdf

Wignjosoebroto, Soetandyo. "Hak Asasi Manusia, Konsep Dasar dan Perkembangan Pengertiannya dari Masa ke Masa", Seri Bahan Bacaan Kursus HAM untuk Pengacara XVI tahun 2007, Lembaga Studi dan Advokasi Masyarakat (ELSAM). Dokumen dapat diakses di www.elsam.or.id.

Wignjosoebroto, Soetandyo. Hukum: Paradigma, Metode, dan Dinamika Masalahnya. Jakarta: Elsam \& Huma, t.t.

Zhang, Y. "Comparative Studies on Judicial Review in East and Southeast Asia", IIAS Symposium, 31 August-1 September, 1995, Leiden, The Netherlands. Diakses dari: http://www.iias.nl/iiasn/iiasn6/iiasnew s/zhang.html

http://www.state.gov/documents/organizatio n/171657.pdf

http://thelawdictionary.org/judicial-review/

Piagam Perserikatan Bangsa-Bangsa (Charter of the United Nations) 1945
International Covenant on Civil and Political Rights (ICCPR)

International Covenant on Economic, Social and Cultural Right (ICESCR)

Undang-Undang Dasar Negara Republik Indonesia 1945

Surat Keputusan Bersama (SKB) Menteri Agama Nomor: 3 Tahun 2008, Jaksa Agung Nomor: Kep-033/A/Ja/6/2008, dan Menteri Dalam Negeri Republik Indonesia Nomor: 199 Tahun 2008 